\title{
Renal threshold of glucose
}

National Diabetes Information Clearinghouse (NDIC)

\section{Definitions}

Blood glucose

Defined by National Diabetes Information Clearinghouse (NDIC)

Kidney

Defined by National Diabetes Information Clearinghouse (NDIC)

\section{Glucose}

Defined by National Diabetes Information Clearinghouse (NDIC)

Urine

Defined by National Diabetes Information Clearinghouse (NDIC)

\section{Source}

National Diabetes Information Clearinghouse (U.S.). (2009). The diabetes dictionary. [Bethesda, Md.]: U.S. Dept. of Health and Human Services, National Institutes of Health, National Institute of Diabetes and Digestive and Kidney Diseases, National Diabetes Information Clearinghouse.

The blood glucose concentration at which the kidneys start to excrete glucose into the urine. 